Regular Article

pISSN: 2288-9744, eISSN: 2288-9752

Journal of Forest and Environmental Science

Vol. 30, No. 4, pp. 351-361, November, 2014

http://dx.doi.org/10.7747/JFES.2014.30.4.351

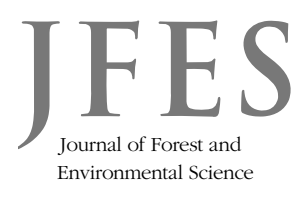

\title{
Allometric Modeling for Leaf Area and Leaf Biomass Estimation of Swietenia mahagoni in the North-eastern Region of Bangladesh
}

\author{
Niamjit Das* \\ Department of Forestry and Environmental Science, Shahjalal University of Science and Technology, Sylhet-3114, Bangladesh
}

\begin{abstract}
Leaf area $\left(A_{0}\right)$ and leaf biomass $\left(M_{0}\right)$ estimation are significant prerequisites to studying tree physiological processes and modeling in the forest ecosystem. The objective of this study was to develop allometric models for estimating $A_{o}$ and $M_{o}$ of Swietenia mahagoni L. from different tree parameters such as DBH and tree height of mahogany plantations in the northeastern region of Bangladesh. A total of 850 healthy and well formed trees were selected randomly for sampling in the five study sites. Then, twenty two models were developed based on different statistical criteria that propose reliable and accurate models for estimating the $A_{o}$ and $M_{0}$ using non-destructive measurements. The results exposed that model iv and $\mathrm{xv}$ were selected on a single predictor of $\mathrm{DBH}$ and showed more statistically accuracy than other models. The selected models were also validated with an additional test data set on the basis of linear regression and t-test for mean difference between observed and predicted values. After that, a comparison between the best logarithmic and non-linear allometric model shows that the non-linear model produces systematic biases and underestimates $A_{O}$ and $M_{0}$ for larger trees. As a result, it showed that the bias-corrected logarithmic model iv and xv can be used to help quantify forest structure and functions, particularly valuable in future research for estimating $A_{O}$ and $M_{O}$ of $S$. mahagoni in this region.
\end{abstract}

Key Words: leaf area, leaf biomass, DBH, Swietenia mahagoni

\section{Introduction}

The leaf area $\left(A_{0}\right)$ of individual trees and of forests is biological factor that determines the light interception and the efficiency of the photosynthetic and transpiration rate (Pereira et al. 1997) and also valuable for gap models and individual tree growth models (Peter et al. 2010). Leaf area is defined as the surface area available for the interception of radiant energy, the absorption of carbon dioxide, and the circulation of water between the foliage and the atmosphere (Margolis et al. 1995) and the plant leaf area is crucial for the evaluation and understanding of the vegetative growth and water loss from the plant. Canopy leaf biomass is the product of the leaf dry matter content and leaf area index (Tobin et al. 2006) and it constitutes one of the most important pools of essential nutrients, which is vital for forest nutrient cycling including carbon cycling. Leaf biomass $\left(M_{0}\right)$ estimates were significantly improved when additional biometric information relating to crown structure was added (Tobin et al. 2006).

Both $A_{0}$ and $M_{0}$ estimations aid evaluation of plant performance at the individual, community and even ecosystem

Received: July 29, 2013. Revised: May 11, 2014. Accepted: May 19, 2014.

Corresponding author: Niamjit Das

Department of Forestry and Environmental Science, Shahjalal University of Science and Technology, Sylhet-3114, Bangladesh

Tel: 88-01737052915, Fax: 88-06919-669596, E-mail: niamjit.forestry@gmail.com 
level (Meier and Leuschner 2008). Moreover, a number of studies ranging from insect-forest interactions (Paine et al. 1990), light competition (Waring 1983), and direct manipulative studies focused on $A_{0}$ response to thinning and fertilization (Vose and Allen 1988; Velazquez-Martinez et al. 1992) have used $A_{0}$ estimates. Inter-specific variation in $A_{0}$ is connected with climatic variation, geology, altitude or latitude whereas this variation can also be linked to allometric factors (plant size, twig size, anatomy and architecture) and ecological strategy (Cornelissen et al. 2003). Ao measurements have become major tools for forest ecosystem and silvicultural studies over the last few decades.

Total $A_{0}$ and $M_{0}$ of trees have been measured by either destructive (direct) (Calvo-Alvarado et al. 2008; Peter et al. 2010) or nondestructive (indirect) (Norman and Campbell 1989; Sarker et al. 2013; Das 2014) methods. Measurement of the destructive method is very time consuming, labour intensive, eco-unfriendly and depends on very small samples. But, nondestructive methods were found user friendly, less expensive, and can give accurate $A_{1}$ and $B_{1}$ estimates (Waring 1983; Norman and Campbell 1989; Paine et al. 1990; Sarker et al. 2013; Das 2014). For the estimation of allometric models are particularly in statistical shape analysis for its theoretical developments (Zianis 2005) and it is unquestionable that researchers have produced a voluminous amount of allometric relationships for several species and tree components (Calvo-Alvarado et al. 2008; Peter et al. 2010). To quantify the $A_{0}$ and $M_{0}$ of individual trees with $\mathrm{DBH}$ (diameter at breast height) of allometric relationship have been widely used (Gajardo-Caviedes et al. 2005). Generally, allometric models are developed by fitting a linear relationship between log-transformed diameter and leaf data.

Tree species of Swietenia mahagoni L. is largely planted on barren forest lands and roadsides in connection with the agroforestry and social forestry programs in Bangladesh (Das and Alam 2001). A substantial portion of the total afforested area (11\%) is located in the north-eastern region of Bangladesh. Though there is no scientific record yet, my experience is that $S$. mahagoni covers a considerable portion of the forest cover of this region. It has great potential for reforestation and afforestation, particularly for improving soil and environmental conditions. In this study, I evaluate several models based on different statistical criteria that propose reliable and accurate models for estimating the $A_{0}$ and $M_{0}$ using non-destructive measurements. Thus, the objective of this study was to develop allometric models for estimating $A_{0}$ and $M_{0}$ of $S$. mahagoni from different tree parameters such as $\mathrm{DBH}$ and tree height of mahogany plantations in the north-eastern region of Bangladesh.

\section{Materials and Methods}

\section{Site description}

The research was conducted on the five sites of Sylhet Forest division, named Kamalganj, Rajkandi, Kulaura, Juri and Barlekha, which are in the Moulovibazar District of north-eastern Bangladesh (Fig. 1). The area lies between 24.11 and $24.42^{\circ} \mathrm{N}$ and between 91.45 and $92.15^{\circ} \mathrm{E}$. This district is located in the semi-evergreen hill forest zone and the characteristic vegetation comprises deciduous to semi-evergreen species in natural forest patches with a closed canopy. The average annual rainfall is $4150 \mathrm{~mm}$ and the relative humidity is about 72 percent during December and over 92 percent during July-August. Forests in this area occupy gentle to very steep slopes. Soils have developed over consolidated or unconsolidated bedrocks, and are imperfect to excessively drain. Generally, the subsoil is yellow to strong brown, friable, porous, sandy loam to sandy or silty clay loam, and strongly to extremely acidic (Banglapedia 2003).

\section{Species description}

Sroietenia mahagoni (L.) is a tall tree, up to $30 \mathrm{~m}$ high, with a short, buttressing base, up to $1 \mathrm{~m}$ in diameter and a large, spherical crown, many heavy branches and dense shade. The tree is deciduous in areas where it is subject to drought. Its leaves even, pinnate, $10-18 \mathrm{~cm}$ long, and bearing 4-10 pairs of leaflets that are shiny, dark green, lance-shaped, 2.5-5 cm long by 0.7-2 cm broad (Das and Alam 2001). S. mahagoni is suitable for large-scale timber production plantations because of its excellent timber quality. The wood can be used for construction materials, plywood (veneer), high-grade furniture and cabinet making. It grows naturally in tropical America and it has been extensively planted mainly in Southern Asia and the Pacific including India, Bangladesh, Indonesia, Philippines and Sri Lanka (Soerianegara and Lemmens 1993). 


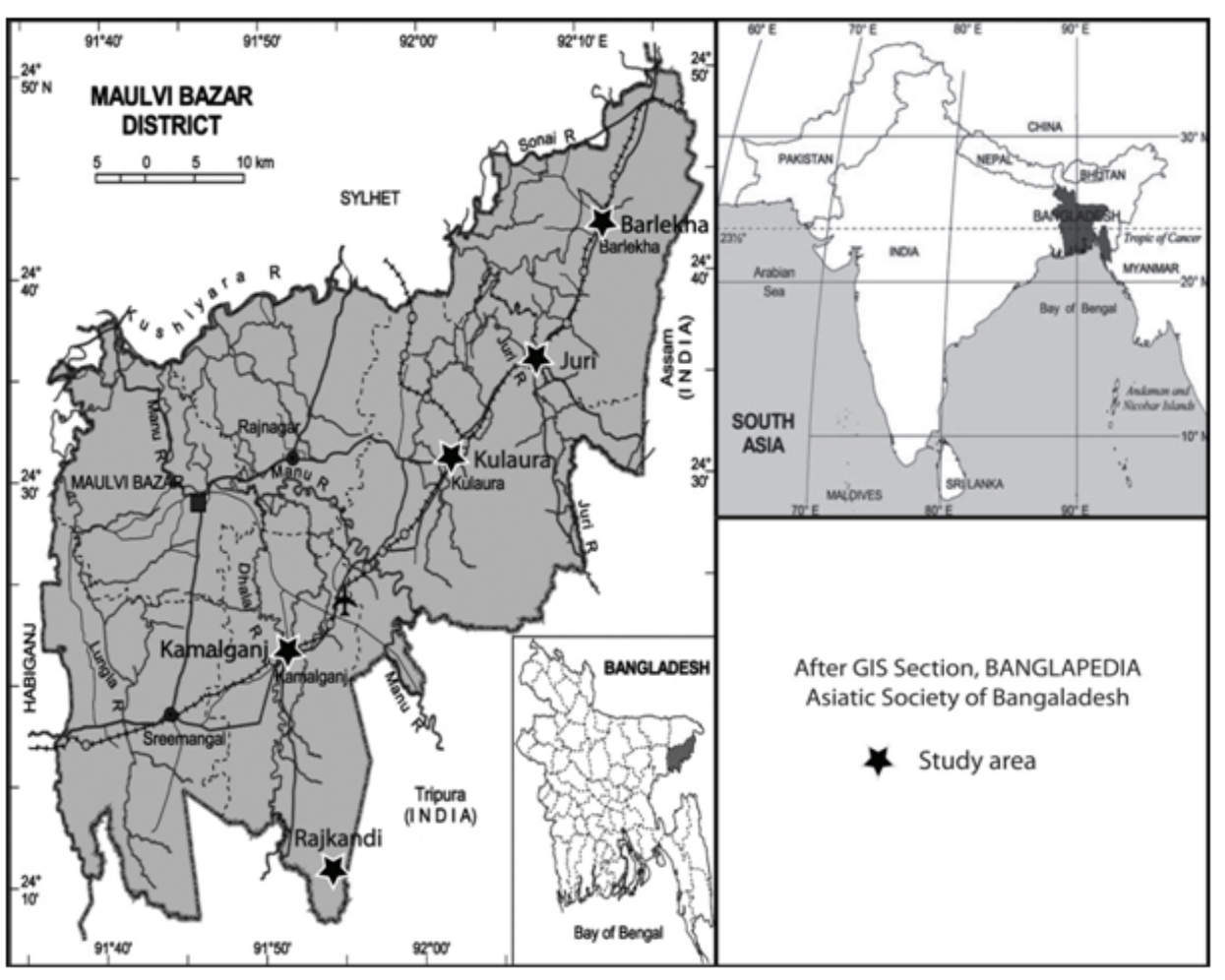

Fig. 1. Map of the Study site.

Table 1. Descriptive statistics for the different variables of S. mahagoni

\begin{tabular}{lcccrcc}
\hline \multicolumn{1}{c}{ Variables } & Mean & Maximum & Minimum & SD & Skewness & Kurtosis \\
\hline DBH $(\mathrm{cm})$ & 26.625 & 53.10 & 10.09 & 10.070 & 0.181 & -0.733 \\
Height $(\mathrm{m})$ & 10.190 & 18.86 & 4.97 & 3.069 & 0.742 & -0.433 \\
Validation DBH $(\mathrm{cm})$ & 23.731 & 51.40 & 11.24 & 13.173 & 0.185 & -0.750 \\
Validation Height $(\mathrm{m})$ & 9.890 & 17.25 & 5.02 & 2.192 & 0.683 & -0.427 \\
Individual leaf area $\left(\mathrm{cm}^{2}\right)$ & 25.517 & 34.37 & 10.36 & 3.614 & 0.238 & 0.217 \\
Individual dry leaf biomass $(\mathrm{g})$ & 0.492 & 0.782 & 0.21 & 0.282 & 0.116 & 0.105 \\
\hline
\end{tabular}

\section{Field measurements}

A total of 850 healthy and well formed $S$. mahagoni trees were selected randomly for sampling. Data on tree height and DBH (Table 1) were measured by Sunnto Clinometers and Tree Calipers. The leaves were collected by using the protocols of Cornelissen et al. (2003). But, because of moratorium on felling in the forests (Sarker et al. 2011), the leaf data was collected manually (climbing on tree). To retain high data accuracy, I used stratified random sampling in calculating leaf number of individual trees. The method is equally suitable to estimate $A_{0}$ where randomly sub-sam- pled branches are used to calculate whole-tree $A_{0}$ based on the relative importance of the branches (Peter et al. 2010; Das 2014). I maintained the following steps to count the leaves of each sampled trees: (I) diameter of all the main branches were measured, (II) main branch's diameter near to mean diameter was selected as model main branch (MMB), (III) sub-branches of all the main branches were counted, (IV) three sub-branches were selected randomly from the MMB, (V) twigs of each sub-branch were counted and mean twigs number/sub-branch was calculated, (VI) thee twigs were selected randomly from each selected sub-branch, (VII) average leaves/twig was calculated, 
(VIII) leaf number/sub-branch was calculated by multiplying mean twigs number/sub-branch and mean leaf numbers/twig and (IX) total leaf number of a tree was calculated by multiplying total sub-branches and estimated leaf number/sub-branch (Sarker et al. 2013; Das 2014). The leaves were categorized into small, medium and large size and five leaves of each category were collected randomly from sub-branches. In total, fifteen leaf samples were collected from each tree and packed in a plastic bag. After that, data of $\mathrm{DBH}$, tree height, leaf samples and total leaf number per tree from an additional 200 trees were collected and used as a test data set for validating the models. Leaf area of each sample leaf (Table 1) was measured by leaf area meter (CI-202, CID, Inc., Vancouver, Washington, USA) and the fresh mass of each leaf was measured with a digital balance meter. Thickness of each sample leaf was estimated with digital caliper (Absolute Digimatic CD-6" CS, Mitutoyo Corporation, Kanagawa, Japan). Measured leaves were oven dried at $65^{\circ} \mathrm{C}$ for 72 hours and weighted to determine fresh mass: dry mass ratios. The projected leaf area for each sample tree $\left(A_{0}, \mathrm{~m}^{2}\right)$ was calculated by multiplying average $A_{0}$ and total leaf number. Total leaf volume/tree was estimated by multiplying total $A_{0}$ and leaf thickness. Leaf density was measured by dividing the average leaf fresh mass by leaf volume of the fifteen sampled leaves per tree. Total leaf biomass per tree was estimated by multiplying the total leaf volume and leaf density (Sarker et al. 2013; Das 2014).

\section{Model development and validation}

From Fig. 2, it was clear that both $\mathrm{DBH}$ and tree height of the model data set were not normally distributed (for DBH: Shapiro-Wilk $\mathrm{p}=5.536 \mathrm{e}-06$; for tree height $\mathrm{p}=$ $3.491 \mathrm{e}-05$ at $\mathrm{a}=0.05)$. For estimation of $A_{0}$ and $M_{0}$ of $S$. mahagoni, I tested of four regression models (linear, power, exponential and quadratic). Total twenty two models were developed using DBH and height for the best allometric relationship between the response and predictors (Table 2). Diagnostic residual plots were used to check five statistical assumptions (Robinson and Hamann 2011), such as I) the models detain a relationship, II) errors have constant variance, III) errors are normally distributed, IV) sample represents the population and $\mathrm{V}$ ) error terms are independent. The developed models were evaluated by examining root mean squared error (RMSE), goodness of fit $\left(R^{2}\right)$, Akaike information criterion (AIC), Bayesian information criterion (BIC) and average deviation (\%). The Durbin-Watson test for autocorrelation was used to check the autocorrelation. Due to the presence of heteroscedasticity, I transformed the data for linear regression using natural logarithm and this transformation induced a systematic bias in the estimation which was corrected using a correction factor (CF) when back transforming the calculation into $A_{0}$ and $M_{0}$ (Son et al. 2001; Sah et al. 2004; Chave et al. 2005). Thus, the correction factor $(\mathrm{CF})$ is calculated according to the usual formula (Sprugel 1983):
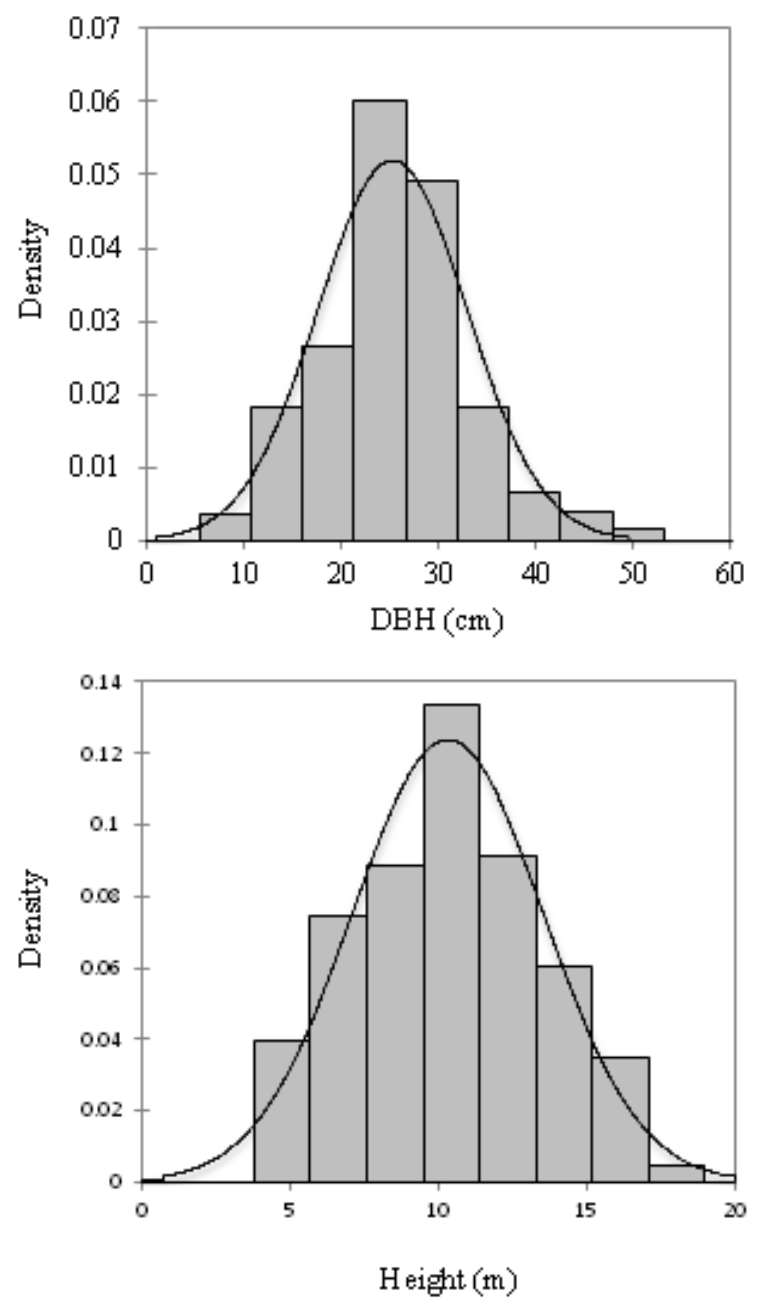

Fig. 2. Diameter at breast height $(\mathrm{DBH} ; \mathrm{cm})$ and tree height $(\mathrm{m})$ distributions of the model fitting data set. 
Table 2. Different models used in this study

\begin{tabular}{|c|c|}
\hline Model no. & Allometric models \\
\hline $\mathrm{i}$ & $\mathrm{LA}=a+b * \mathrm{DBH}$ \\
\hline ii & $\mathrm{LA}=a+b * \mathrm{H}$ \\
\hline iii & $\mathrm{LA}=a+b * \mathrm{DBH}+c^{*} \mathrm{H}$ \\
\hline iv & $\operatorname{lnLA}=a+b * \ln \mathrm{DBH}$ \\
\hline $\mathrm{v}$ & $\ln \mathrm{LA}=a+b * \ln \mathrm{H}$ \\
\hline vi & $\ln \mathrm{LA}=a+b * \ln \mathrm{DBH}+c^{*} \ln \mathrm{H}$ \\
\hline vii & $\operatorname{lnLA}=a+b * \mathrm{DBH}$ \\
\hline viii & $\ln L A=a+b * \mathrm{H}$ \\
\hline ix & $\ln \mathrm{LA}=a+b * \mathrm{DBH}+c^{*} \mathrm{H}$ \\
\hline $\mathrm{x}$ & $\ln \mathrm{LA}=a+b * \mathrm{DBH}+c^{*} \mathrm{DBH}^{2}$ \\
\hline $\mathrm{xi}$ & $\ln \mathrm{LA}=a+b * \mathrm{H}+c^{*} \mathrm{H}^{2}$ \\
\hline xii & $\mathrm{FB}=a+b * \mathrm{DBH}$ \\
\hline xiii & $\mathrm{FB}=a+b * \mathrm{H}$ \\
\hline xiv & $\mathrm{FB}=a+b * \mathrm{DBH}+c^{*} \mathrm{H}$ \\
\hline $\mathrm{xv}$ & $\ln \mathrm{FB}=a+b^{*} \ln \mathrm{DBH}$ \\
\hline xvi & $\ln \mathrm{FB}=a+b^{*} \ln \mathrm{H}$ \\
\hline xvii & $\ln \mathrm{FB}=a+b * \ln \mathrm{DBH}+c^{*} \ln \mathrm{H}$ \\
\hline xviii & $\ln \mathrm{FB}=a+b * \mathrm{DBH}$ \\
\hline xix & $\ln \mathrm{FB}=a+b^{*} \mathrm{H}$ \\
\hline $\mathrm{xx}$ & $\ln \mathrm{FB}=a+b * \mathrm{DBH}+c * \mathrm{H}$ \\
\hline xxi & $\ln \mathrm{FB}=a+b * \mathrm{DBH}+c^{*} \mathrm{DBH}^{2}$ \\
\hline xxii & $\ln \mathrm{FB}=a+b^{*} \mathrm{H}+c^{*} \mathrm{H}^{2}$ \\
\hline
\end{tabular}

$$
\mathrm{CF}=\exp ^{\left(\left(S E E^{*} 2.303\right)^{2} / 2\right)}
$$

where $\mathrm{SEE}=$ standard error of the estimate. The average deviation was computed from the absolute difference between predicted and observed values and expressed as the percentage of observed values, and then all deviations were averaged (Cairns et al. 2003; Chave et al. 2005). The average deviation $(\delta \mathrm{B})$ is calculated as follows:

$$
\underset{\mathrm{n}=1}{\mathrm{n} \mathrm{B}}(\%)=\sum|\check{\mathrm{D}} \mathrm{W}-\mathrm{DW}| / \mathrm{DW}^{*}(100 / \mathrm{n})
$$

where $\check{\mathrm{DW}}=$ estimated, DW= observed and $\mathrm{n}=$ number of observations. It was calculated after the prediction was back-transformed to the unit values and corrected using a CF. This model was then compared with the relevant logarithmic model with bias correction.

I used R statistical software version 3 (R Development Core Team 2013) for data analysis. I regressed the observed $A_{0}$ and $M_{0}$ of the test data from an additional test data set ( $\mathrm{n}$ $=200)$ against the predicted $A_{0}$ and $M_{0}$ uses linear re- gression for validating the models. Then, I compared the mean difference between the observed and predicted $A_{0}$ and $M_{0}$ using a $t$-test. In addition, I developed best fit non-linear regression model for estimating $A_{0}$ and $M_{0}$ and these models were then compared to the bias corrected logarithmic models.

\section{Results}

\section{Model development and evaluation}

From the development of twenty two models, the best ones were determined according to the selection criteria described in materials and methods and the $A_{0}$ and $M_{0}$ were best estimated using models iv and xv, respectively (Table $3)$. For both parameters, the goodness of fit adjusted $\left(R^{2}\right)$ of regressions was highly significant while using the $\mathrm{DBH}$ as a predictor and explained more than $93 \%$ variation. To compare the models, the AIC and BIC values for models iv and $\mathrm{xv}$ were lower than that of other tested models indicating the statistical robustness of the selected models (iv and $\mathrm{xv}$ ) and the RMSE values were also lower for the selected models (Table 3). Among the tested models, model iv and $\mathrm{xv}$ had the lowest average deviations (17.304 and 20.447\%, respectively).

To check these statistical assumptions, for first assumption, I plotted regression residuals versus fitted values for the models in order to check whether the linear model captures the relationship. In this scatter plot, I noted that the residual scatter plot had the slight heteroscedastic behavior of the selected models (Figs. 3A, 4A). After that, I also plotted the normal Q-Q plot of the standardized residuals against the normal distribution line and the errors showing slight departure from the line (Figs. 3B, 4B) that have constant variance (assumption II) and were normally distributed (assumption III). In addition, to check assumption II, I plotted the square root of the absolute residuals against the fitted values (Figs. 3C, 4C), and the figures show no deviations from the horizontal line. However, such kind of deviations from the horizontal line is often acceptable as described in large sample theory (Robinson and Hamann 2011). The leverage of the observations against the standardized residuals showed that the Cook's distance was less than 1 in both cases (Figs. 3D, 4D). This indicates that the adequacy of the sample as a representative of the population 
Table 3. Estimated parameters of the different models tested for predicting $A_{0}$ and $M_{0}$ of $S$. mahagoni

\begin{tabular}{|c|c|c|c|c|c|c|c|c|c|c|c|c|}
\hline \multirow{2}{*}{ Model - } & \multicolumn{3}{|c|}{ Estimated Coefficients } & \multirow{2}{*}{ RMSE } & \multirow{2}{*}{ F } & \multirow{2}{*}{$R^{2}$} & \multirow{2}{*}{$\begin{array}{c}\text { Adjusted } \\
R^{2}\end{array}$} & \multirow{2}{*}{ AIC } & \multirow{2}{*}{ BIC } & \multirow{2}{*}{$\mathrm{CF}$} & \multirow{2}{*}{$\mathrm{AD}$} & \multirow{2}{*}{$\begin{array}{l}\text { Durbin } \\
\text { Watson }\end{array}$} \\
\hline & $\mathrm{a}$ & $\mathrm{b}$ & c & & & & & & & & & \\
\hline i & $-83.3269 * * *$ & $7.10880 * * * *$ & & 20.112 & 5,924 & 0.8953 & 0.8951 & $6,144.42$ & $6,161.74$ & - & 40.246 & 1.036 \\
\hline ii & $-105.352 * *$ & $24.978^{* *}$ & & 45.311 & 611 & 0.4687 & 0.4679 & $7,269.56$ & $7,290.38$ & - & 135.15 & 1.494 \\
\hline iii & $-80.5471 * * *$ & $7.2174 * * *$ & -0.7196 & 20.117 & 2,963 & 0.8955 & 0.8951 & $6,145.83$ & $6,167.09$ & - & 42.368 & 1.073 \\
\hline iv & $-2.96749 * * *$ & $2.28677 * * *$ & & 0.2096 & 12,140 & 0.9460 & 0.9459 & -192.58 & -182.06 & 1.0222 & 17.304 & 1.957 \\
\hline $\mathrm{v}$ & $-2.12996 * *$ & $3.12390 * * *$ & & 0.5790 & 988 & 0.5878 & 0.5872 & $1,211.27$ & $1,230.29$ & 1.1824 & 64.803 & 2.113 \\
\hline vi & $-3.07579 * * *$ & $2.20725 * * *$ & $0.17899^{* * *}$ & 0.2099 & 6,154 & 0.9428 & 0.9426 & -190.63 & -180.71 & 1.0229 & 18.990 & 1.904 \\
\hline vii & $1.681304 * * *$ & $0.102639 * * * *$ & & 0.3041 & 5,400 & 0.8863 & 0.8861 & 317.79 & 335.44 & 1.0473 & 19.682 & 0.960 \\
\hline viii & $1.17847^{* * * *}$ & $0.38620 * * * *$ & & 0.6169 & 788 & 0.5321 & 0.5314 & $1,297.46$ & $1,318.47$ & 1.2095 & 56.238 & 1.867 \\
\hline ix & $1.507932 * * *$ & $0.095863^{* * * *}$ & $0.0448 * * *$ & 0.2999 & 2,788 & 0.8896 & 0.8893 & 298.94 & 321.38 & 1.0459 & 18.027 & 0.969 \\
\hline $\mathrm{x}$ & $0.4893^{* * * *}$ & $0.2127 * * *$ & $-0.002 * * *$ & 0.2246 & 5,243 & 0.9381 & 0.9379 & -95.25 & -80.68 & 1.0255 & 30.912 & 1.726 \\
\hline xi & $-3.75163 * * *$ & $1.681444 * * *$ & $-0.081 * * *$ & 0.5522 & 578 & 0.6256 & 0.6245 & $1,145.10$ & $1,170.02$ & 1.1646 & 84.165 & 2.250 \\
\hline xii & $-7.20572 * * *$ & $0.636409^{* * * *}$ & & 2.0460 & 4,588 & 0.8688 & 0.8686 & $2,968.41$ & $2,985.02$ & - & 35.682 & 1.465 \\
\hline xiii & $-9.29298 * *$ & $2.25213 * *$ & & 4.1451 & 593 & 0.4613 & 0.4606 & $3,947.66$ & $3,966.41$ & - & 122.29 & 1.585 \\
\hline xiv & $-7.09026 * * * *$ & $0.64092 * * *$ & -0.02989 & 2.0471 & 2,291 & 0.8688 & 0.8684 & $2,966.38$ & $2,991.36$ & - & 38.431 & 1.478 \\
\hline $\mathrm{xv}$ & $-5.22514 * * *$ & $2.25004 * * * *$ & & 0.2430 & 8,740 & 0.9365 & 0.9364 & 9.42 & 23.61 & 1.0299 & 20.447 & 2.014 \\
\hline xvi & $-4.42117 * * *$ & $3.08403 * * *$ & & 0.5813 & 955 & 0.5796 & 0.5790 & $1,214.47$ & $1,235.95$ & 1.1840 & 64.988 & 2.105 \\
\hline xvii & $-5.34700 * * *$ & $2.16057 * * *$ & $0.20141^{* *}$ & 0.2455 & 4,429 & 0.9275 & 0.9273 & 10.49 & 25.56 & 1.0305 & 20.982 & 1.965 \\
\hline xviii & $-0.64179 * * *$ & $0.100578 * * *$ & & 0.3343 & 4,291 & 0.8610 & 0.8608 & 451.24 & 466.98 & 1.0574 & 21.994 & 1.103 \\
\hline xix & $-1.14913 * *$ & $0.38047 * *$ & & 0.6196 & 758 & 0.5224 & 0.5217 & $1,305.73$ & $1,324.61$ & 1.2116 & 45.681 & 1.858 \\
\hline $\mathrm{xx}$ & $-0.82855 * * *$ & $0.093279 * * * *$ & $0.0483 * * * *$ & 0.3298 & 2,214 & 0.8649 & 0.8645 & 431.82 & 453.74 & 1.0558 & 23.627 & 1.112 \\
\hline xxi & $-1.90365 * * *$ & $0.217069 * * *$ & $-0.002 * * * *$ & 0.2542 & 3,964 & 0.9197 & 0.9195 & 72.55 & 91.84 & 1.0328 & 37.416 & 1.850 \\
\hline xxii & $-6.22750 * * *$ & $1.714661 * * * *$ & $-0.082 * * *$ & 0.5511 & 571 & 0.6228 & 0.6217 & $1,141.89$ & $1,167.11$ & 1.1639 & 98.243 & 2.268 \\
\hline
\end{tabular}

*p $<0.01, * * \mathrm{p}<0.001, * * \mathrm{p}<0.0001$.

$\mathrm{AD}=$ Average deviation $(\%), \mathrm{CF}=$ Correction factor.

(assumption IV). The basic diagnostic plot cannot check assumption $\mathrm{V}$ because it doesn't have the option to check the independence of the error terms. To check this assumption, the Durbin-Watson test for autocorrelation among the residuals showed that the selected models were 1.957 and 2.014 for $A_{0}$ and $M_{0}$, respectively and nearly lies within the range of the acceptable limit of 2 . In this context, the model coefficients cannot be reliably used unless the correction factor is applied to remove the heteroscedasticity. Correction factors showed a rather narrow variation for both cases (Table 3).

Therefore, the final model of $A_{0}$ is, $A_{0}=\exp (-2.96749+$ $2.28677 x \ln (\mathrm{DBH}))$, which can be written as $A_{0}=$ $0.051432 \times(\mathrm{DBH})^{2.28677}$. The bias corrected model is, $A_{0}$ $=0.051432 \times(\mathrm{DBH})^{2.28677} \times 1.0222$, and the final form of this model is $A_{0}=0.052574 \mathrm{x}(\mathrm{DBH})^{2.28677}$.

The final model of leaf biomass is, $M_{0}=\exp (-5.22514$ $+2.25004 x \ln (\mathrm{DBH}))$, and can be written as $M_{0}=$ $0.00538 \mathrm{x}(\mathrm{DBH})^{2.25004}$. The bias corrected model is, $M_{0}$ $=0.00538 \mathrm{x}(\mathrm{DBH})^{2.25004} \times 1.0299$, which finally formed as
$M_{0}=0.00554 \times(\mathrm{DBH})^{2.25004}$.

\section{Model performance estimation}

In the model validation, the goodness of fit $\left(R^{2}\right)$ showed that there was a highly reliable relationship between estimated and observed data for both cases $\left(A_{0}\right.$ and $\left.M_{0}\right)$. The $\mathrm{R}^{2}$ between them for models using $A_{0}$ and $M_{0}$ was 0.982 and 0.965 , respectively (Fig. 5). At $95 \% \mathrm{CI}$, the mean of the observed and the proposed models predicted data were not significantly different $\left(\mathrm{p}=0.998\right.$ for $A_{0}$ and $\mathrm{p}=0.993$ for $M_{0}$ ) and there is a high probability that estimated values are closest to the observed values (Table 4 ). The predicted $A_{0}$ and $M_{0}$ using model iv and xv produced the same trend as the observed data (Fig. 6). In addition, I compared the best fitted nonlinear and the bias corrected logarithmic models (Table 5). The adjusted $R^{2}, \mathrm{AIC}$ and BIC values of the non-linear allometric model were $0.944,5531.527$ and 5558.043 for $A_{0}, 0.924,2693.836$ and 2715.838 for $M_{0}$, respectively. On the other hand, for the logarithmic model those were $0.9459,-192.58$ and -182.06 for $A_{0}, 0.9364$, 

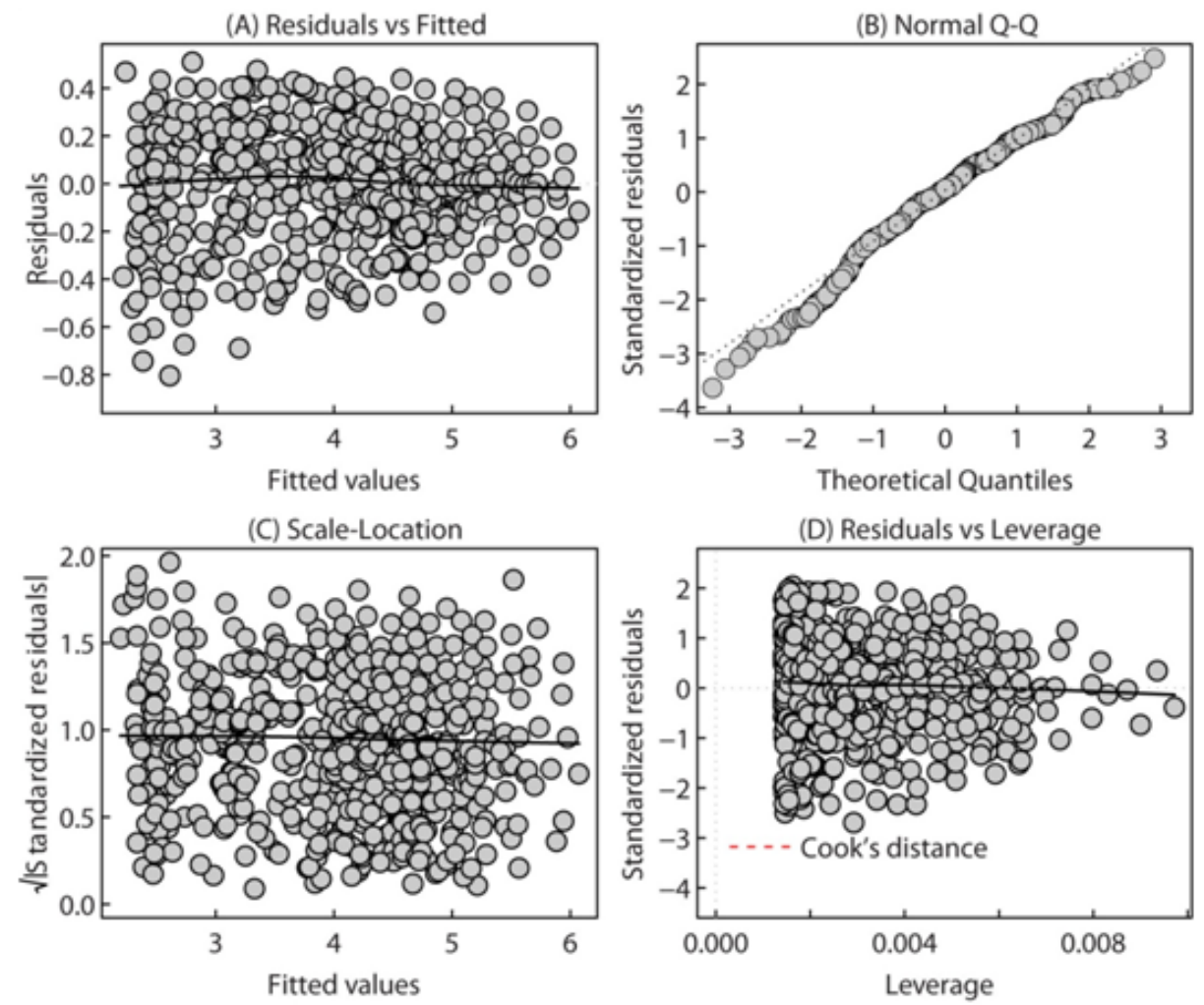

Fig. 3. Diagnostic plots for model iv.
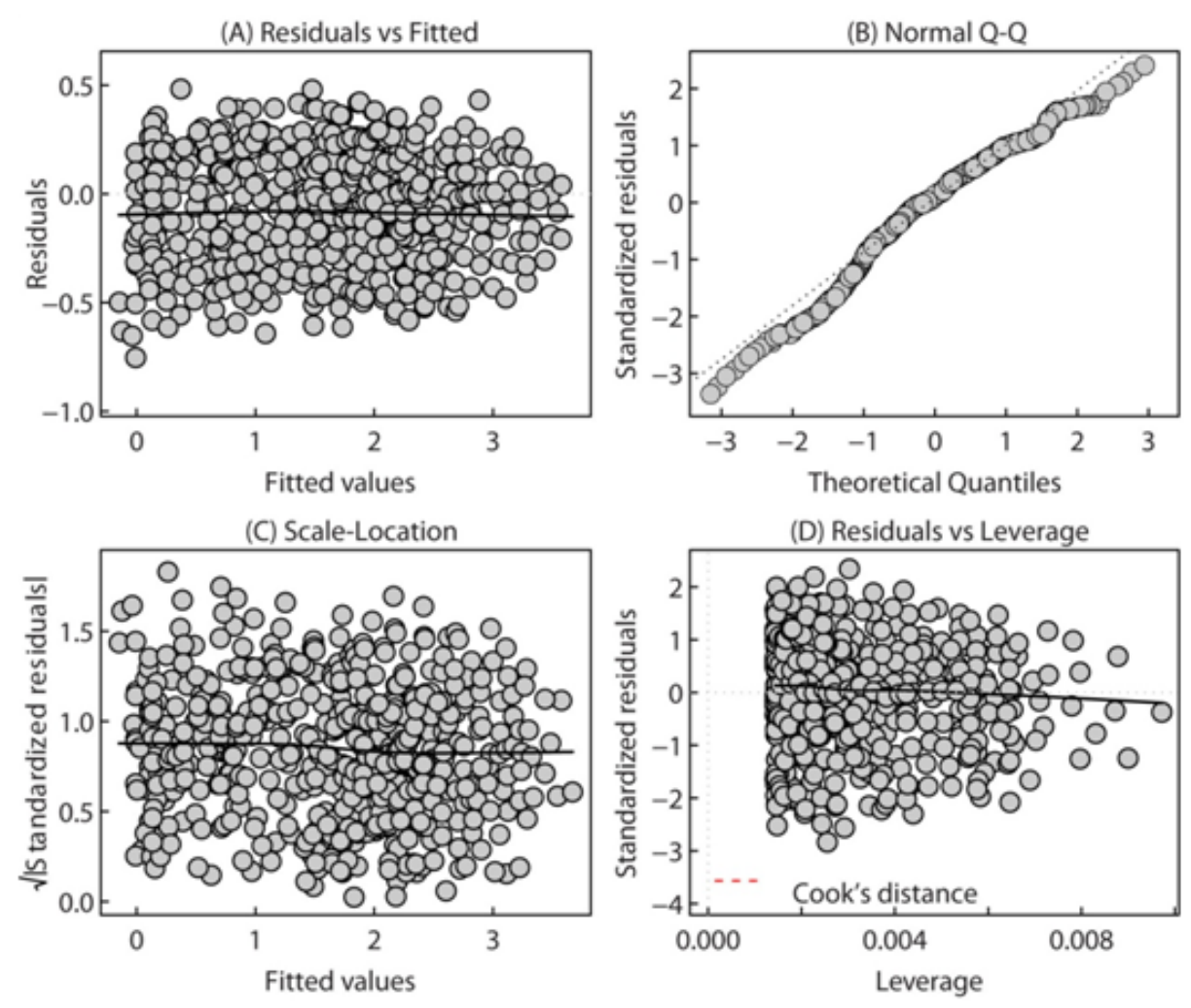

Fig. 4. Diagnostic plots for model xv. 
Allometric Modeling for Leaf Area and Leaf Biomass Estimation of Swietenia mahagoni

Table 4. The confidence interval (CI) of the mean $A_{0}\left(\mathrm{~m}^{2}\right)$ and $M_{0}(\mathrm{~kg})$ for observed and best fit model data, and paired $t$-test for this species

\begin{tabular}{ccccccc}
\hline & Parameters & Observed & Model & SEE & $t$-test & Significance \\
\hline \multirow{3}{*}{$A_{0}$} & Mean & 75.285 & 76.797 & 0.526 & -2.872 & 0.998 \\
& $95 \%$ CI Lower limit & 70.660 & 71.940 & & & \\
& $95 \%$ CI Upper limit & 79.910 & 81.654 & & & 0.993 \\
$M_{0}$ & Mean & 6.993 & 7.164 & 0.068 & -2.480 & \\
& $95 \%$ CI Lower limit & 6.573 & 6.719 & & & \\
& $95 \%$ CI Upper limit & 7.414 & 7.609 & & & \\
\hline
\end{tabular}

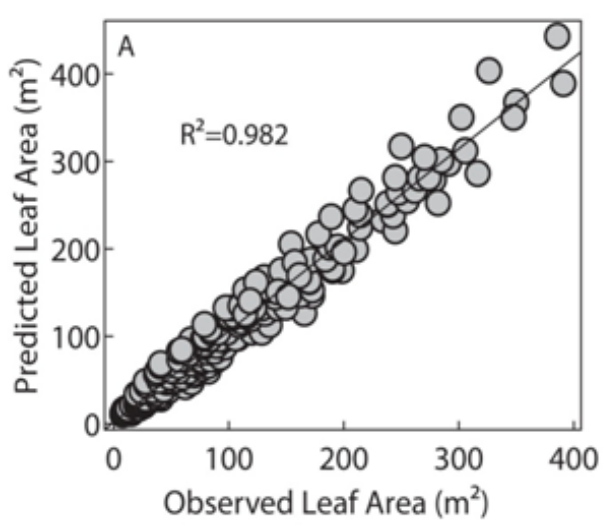

(A) Leaf Area

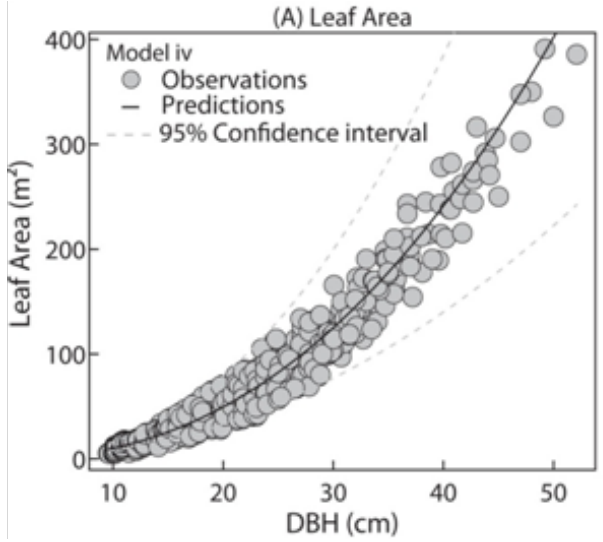

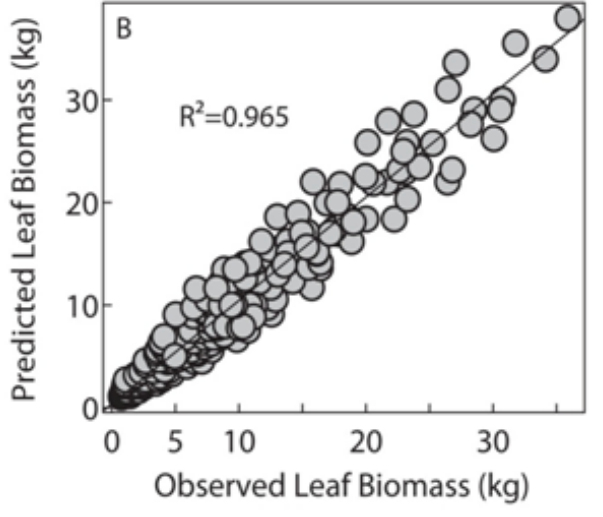

(B) Leaf Biomass

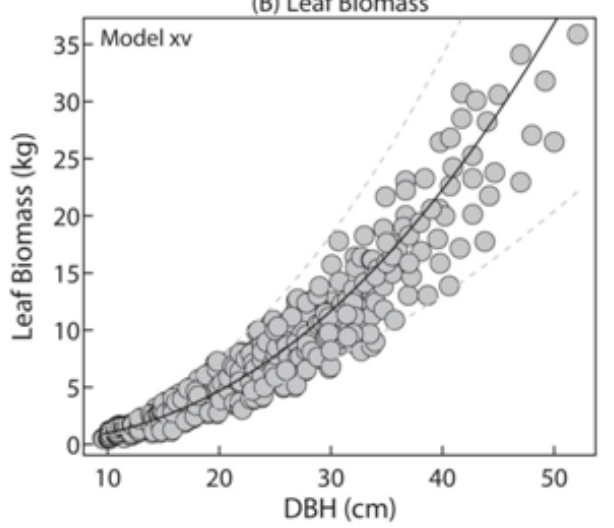

Fig. 5. Linear regression between observed and predicted leaf area (A); between observed and predicted leaf biomass (B).
Fig. 6. Predicted leaf area (A) and leaf biomass (B) against diameter at breast height (DBH) using model iv and xv with observed data at $95 \%$ confidence intervals (CI).
9.42 and 23.61 for $M_{0}$. Despite of similar $R^{2}$ values, the $\mathrm{AIC}$ and BIC values were lower for logarithmic models in both cases. Moreover, nonlinear allometric models showed a propensity of underestimation of $A_{0}$ and $M_{0}$ with an increase of DBH (Fig. 7).

\section{Discussion}

The selected logarithmic models (iv and $\mathrm{xv}$ ) were pro- posed according to slight heteroscedastic residual scatter, lower RMSE, AIC, BIC value and average deviation for estimation of $A_{0}$ and $M_{0}$. Though, logarithmic transformation induces a systematic bias in the estimation, which was corrected using a $\mathrm{CF}$ in the final model (Son et al. 2001; Sah et al. 2004; Chave et al. 2005). Consequently, the bias-corrected final allometric models produced a range of prediction values closer to the upper and lower limits of the observed mean values. These models accounted for more 
Table 5. Estimated parameters for the best fit nonlinear model iv of $A_{0}$ and model xv of $M_{0}$

\begin{tabular}{rlccrc}
\hline & Parameters & Estimate & Std. Error & $t$-value & p-value \\
\hline \multirow{2}{*}{$A_{0}$} & Intercept & 0.074941 & 0.00494 & 15.14 & $<2 \mathrm{e}-16^{* * * *}$ \\
& Power & 2.174058 & 0.01881 & 115.55 & $<2 \mathrm{e}-16^{* * * *}$ \\
$M_{0}$ & Intercept & 0.010102 & 0.00092 & 10.90 & $<2 \mathrm{e}-16^{* * * *}$ \\
& Power & 2.062322 & 0.02625 & 78.54 & $<2 \mathrm{e}-16^{* * * *}$ \\
\hline
\end{tabular}

*** Significant at $\alpha=0.00$.

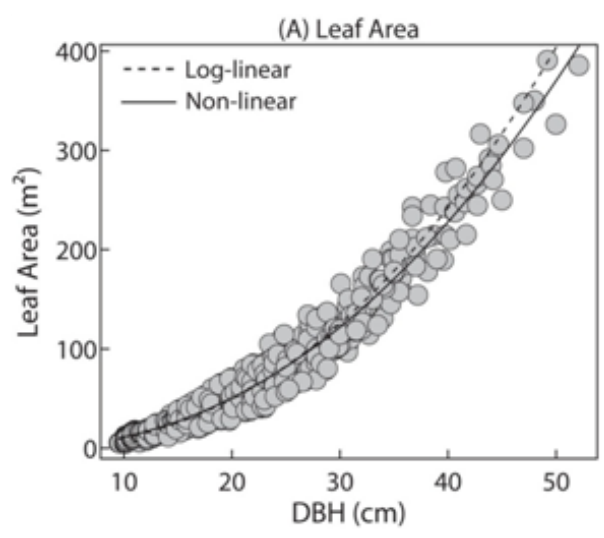

than $93 \%$ variation based on $\mathrm{DBH}$ in $A_{0}$ and $M_{0}$ estimation (Table 3 ), providing a sound and reliable means to predict these canopy properties in the north-eastern region of Bangladesh. Burton et al. (1991) found that DBH is the best predictor for estimating $A_{0}$ and $M_{0}\left(R^{2}>0.90\right)$. After that, the development of $A_{0}$ and $M_{0}$ models using nondestructive methods is a highly steady option where whole tree removal is not possible, as is the case in Bangladeshi forest reserves (Dobbs et al. 2011). Thus, modified randomized branch sampling used in this study will in most cases remain the only feasible method and this study showed a strong statistical dependence between $A_{0}$ and $M_{0}$ with $\mathrm{DBH}$. Using a non-destructive sampling technique for $A_{0}$ estimation, Grace and Fownes (1998) found that DBH could explain $91 \%$ variation in $A_{0}$ of Acacia Koa. Leaf area and biomass are positively related to $\mathrm{DBH}$ (Tobin et al. 2006; Calvo-Alvarado et al. 2008) and Vertessy et al. (1995) showed that DBH could explain more than $91 \%$ of true $A_{0}$ of Eucalyptus regnans. Das (2014) found that the developed models are explained for more than $96 \%$ of the variation based on $\mathrm{DBH}$ and height with $A_{0}$ and $M_{0}$ of Lagerstroemia speciosa. Sarker et al. (2013) also showed that
$\mathrm{DBH}$ could explain $95 \%$ variation in $A_{0}$ and $M_{0}$ of Artocarpus chaplasha. Other studies found higher (Waring et al. 1982; Long and Smith 1988; Fownes and Harrington 1991; Zianis and Mencuccini 2003; Tobin et al. 2006; Peter et al. 2010) correlations with $\mathrm{DBH}$. As a result, the selected allometric models are significant to tree growth models of this species and ecological purposes. It will tend to estimate $A_{0}$ and $M_{0}$ for trees exhibiting leaf loss due to such factors as pruning, insect defoliation etc. After that, I expect these relationships to prove valuable quantification of tree physiological and environmental processes. Therefore, the results obtained support that the regression models can be used on stands of different vigour and it is probably valid in Bangladesh and other tropical countries.

\section{Acknowledgments}

I wish to thank field staffs of the Divisional Forest Office, Sylhet for their assistance during the field works. 


\section{References}

Banglapedia 2003. National Encyclopedia of Bangladesh, vol. 2. Asiatic Society of Bangladesh, Dhaka, pp 34-37.

Burton AJ, Pregitzer KS, Reed DD. 1991. Leaf area and foliar biomass relationships in northern hardwood forests located along an $800 \mathrm{~km}$ acid deposition gradient. For Sci 37: 1041-1059.

Cairns MA, Olmsted I, Granados J, Argaez J. 2003. Composition and above-ground tree biomass of a dry semi-evergreen forest on Mexico's Yucatan Peninsula. For Ecol Manage 186: 125-132.

Calvo-Alvarado JC, McDowell NG, Waring RH. 2008. Allometric relationships predicting foliar biomass and leaf area: sapwood area ratio from tree height in five Costa Rican rain forest species. Tree Physiol 28: 1601-1608.

Chave J, Andalo C, Brown S, Cairns MA, Chambers JQ, Eamus D, Fölster H, Fromard F, Higuchi N, Kira T, Lescure JP, Nelson BW, Ogawa H, Puig H, Riéra B, Yamakura T. 2005. Tree allometry and improved estimation of carbon stocks and balance in tropical forests. Oecologia 145: 87-99.

Cornelissen JHC, Lavorel S, Garnier E, Diaz S, Buchmann N, Gurvich DE, Reich PB, Steege H, Morgan HD, Heijden MGA, Pausas JG, Poorter H. 2003. A handbook of protocols for standardized and easy measurement of plant functional traits worldwide. Aust J Bot 51: 335-380.

Das N. 2014. Modeling develops to estimate leaf area and leaf biomass of Lagerstroemia speciosa in West Vanugach Reserve Forest of Bangladesh. ISRN Forestry 2014: 486478.

Das DK, Alam MK. 2001. Trees of Bangladesh. Bangladesh Forest Research Institute, Chittagong.

Dobbs C, Hernández J, Francisco EF. 2011. Above ground biomass and leaf area models based on a nondestructive method for urban trees of two communes in Central Chile. Bosque 32: 287-296.

Fownes JH, Harrington RA. 1992. Allometry of woody biomass and leaf area in five tropical multipurpose trees. J Trop For Sci 4: 317-330.

Gajardo-Caviedes PA, Espinosa MA, del T González U, Rios DG. 2005. The influence of thinning and tree size on the sapwood area/leaf area ratio in coigue. Can J For Res 35: 1679-1685.

Grace KT, Fownes JH. 1998. Leaf area allometry and evaluation of non-destructive estimates of total leaf area and loss by browsing in a silvopastoral system. Agrofor Syst 40: 139-147.

Long JN, Smith FW. 1988. Leaf area-sapwood area relations of lodge pole pine as influenced by stand density and site index. Can J For Res 18: 247-250.

Margolis H, Oren R, Whitehead D, Kaufmann MR. 1995. Leaf area dynamics of conifer forests. In: Ecophysiology of Coniferous Forests (Smith WK, Hinckley TM, eds). Academic Press, San Diego, pp 255-208.

Meier IC, Leuschner C. 2008. Leaf size and leaf area index in
Fagus sylyatica forests: competing effects of precipitation, temperature and nitrogen availability. Ecosystems 11: 655-669.

Norman JM, Campbell GS. 1989. Canopy structure. In: Plant physiological ecology: Field methods and instrumentation (Pearcy RW, Ehleringer J, Mooney HA, Rundel PW, eds). Chapman and Hall, New York, USA, pp 301-325.

Paine TD, Malinoski MK, Scriven GT. 1990. Rating eucalyptus vigor and the risk of insect infestation: leaf surface area and sapwood: heartwood ratio. Can J For Res 20: 1485-1489.

Pereira AR, Villa nova NA, Sediyama GC. 1997. Evapo(trans) piração. FEALQ, Piracicaba, p 183.

Peter H, Otto E, Hubert S. 2010. Leaf area of beech (Fagus sylvatica L.) from different stands in eastern Austria studied by randomized branch sampling. Eur J For Res 129: 401-408.

R Development Core Team 2013. R: a language and environment for statistical computing. Vienna: R Foundation for Statistical Computing.

Robinson AP, Hamann JD. 2011. Forest analytics with R: an introduction. Springer, New York.

Sah JP, Ross MS, Kaptur S, Snyder JR. 2004. Estimating above-ground biomass of broad leaved woody plants in the understory of Florida Keys pine forests. For Ecol Manage 203: 319-329.

Sarker SK, Das N, Chowdhury MQ, Haque MM. 2013. Developing allometric equations for estimating leaf area and leaf biomass of Artocarpus chaplasha in Raghunandan Hill Reserve, Bangladesh. Southern Forests 75: 51-57.

Sarker SK, Deb JC, Halim MA. 2011. A diagnosis of existing logging bans in Bangladesh. Int For Rev 13: 461-475.

Soerianegara I, Lemmens RHMJ. 1993. Plant resources of South-east Asia 5(1): timber trees: major commercial timbers. Pudoc Scientific Publishers, Wageningen, Netherlands.

Son Y, Hwang JW, Kim ZS, Lee WK, Kim JS. 2001. Allometry and biomass of Korean pine (Pinus koraiensis) in central Korea. Bioresour Technol 78: 251-255.

Sprugel DG. 1983. Correcting for bias in log-transformed allometric equations. Ecology 64: 209-210.

Tobin B, Black K, Osborne B, Reidy B, Bolger T, Nieuwenhuts M. 2006. Assessment of allometric algorithms for estimating leaf biomass, leaf area index and litter fall in different-aged Sitka spruce forests. Forestry 79: 453-464.

Velazquez-Martinez A, Perry DA, Bell TE. 1992. Response of aboveground biomass increment, growth efficiency, and foliar nutrients to thinning, fertilization, and pruning in young Douglas-fir plantations in the central Oregon Cascades. Can J For Res 22: 1278-1289.

Vertessy RA, Benyon RG, O'Sullivan SK, Gribben PR. 1995. Relationships between stem diameter, sapwood area, leaf area and transpiration in a young mountain ash forest. Tree Physiol 15: 559-567.

Vose JM, Allen HL. 1988. Leaf area, stem wood growth, and nutritional relationships in loblolly pine. For Sci 34: 547-563. 
Waring RH. 1983. Estimating forest growth and efficiency in relation to canopy leaf area. In: Advances in Ecological Research (MacFadyen A, Ford ED, eds). Academic Press, New York, USA, pp 327-354.

Waring RH, Schroeder PE, Oren R. 1982. Application of the pipe model theory to predict canopy leaf area. Can J For Res 12: 556-560.
Zianis D. 2005. Aspects of Tree Allometry. New Research on Forest Ecosystems, UK, pp 113-144.

Zianis D, Mencuccini M. 2003. Above ground biomass relationships for beech (Fagus moesiaca Cz.) trees in Vermio Mountain, Northern Greece, and generalized equations for Fagus sp. For Sci 60: 439-448. 